\title{
Socio-Psychological Factors of Preferences Regarding Socio-Economic and Socio-Political Activity of the Russian Provincial Youth
}

\author{
Saratov State University (Russia, Saratov, Astrakhanskaya st., 83) \\ E-mail: shamionov@mail.ru; shamionov@info.sgu.ru
}

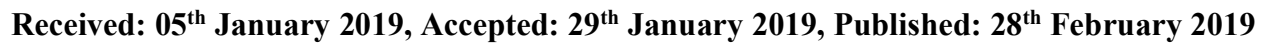

\begin{abstract}
The urgency of the problem lies in the need to analyse socio-psychological determinants of young people's economic and political activity preferences.

The purpose of the study is to investigate the directions of the relationships between preference of socio-economic and socio-political activity among young people and satisfaction of basic needs, riskiness, preference for sources of information about the country's social life, attitudes towards the possibility of participation in social life and social activity in the country of residence.

Methods. 305 people, who filled out the questionnaires, took part in the study, mean age $\mathrm{M}=21.2 \mathrm{SD}=2.9$ (35\% male), $64 \%$ were residents of big cities, 36\% were residents of small towns (up to 100000 residents) from the provincial Russian regions.

As a result of correlation analysis, it was established that commitment to socio-political and socio-economic activity are closely interrelated. However, there are no direct relationships with socio-demographic characteristics and income of the respondents.

Structural modeling helped to determine that the most suitable model $(\chi 2=29.30 ; \mathrm{df}=28 ; \mathrm{p}=.398 ; \mathrm{CFI}=.997 ; \mathrm{GFI}=.983$; RMSEA=.012) includes explanatory variables convictions regarding the capacity to demonstrate social activity in the country, experience of parents' social activity, adherence to specific information sources (radio and organizations' representatives ), satisfaction of basic needs for autonomy and competence, as well as riskiness. The objective explanatory variable is the exogenous variable "age". It allows to identify the communication direction.
\end{abstract}

Keywords

Socio-Economic, Socio-Political, Activity, Young People

\section{Introduction}

The problem of social activity of young people belongs to the scientific focus area of psychology, sociology, law, pedagogics and other sciences. Social activity of young people is an important foundation for society's dynamic and innovative development. Socio-economic and socio-political activity of young people is an important achievement in a democratic society and acts as the engine of serious social processes, changes in political, economic, social and other systems. Since there is a continuous relationship between economic and political processes, these types of social activity of young people should be studied together. The urgency of the problem can be explained by the need to analyse socio-psychological determinants of young people's economic and political preferences. This type of scientific knowledge will help to gain a more thorough understanding of young people's differentiated attitude towards various types of activity, as well as to identify which psychological needs, ideas, beliefs and motives influence their preferences.

Studies of socio-economic and socio-political activity of young people, that have been conducted in sociology, social psychology, and political science, testify to their ambiguous correlation. As researchers note, the homo economicus model as a model of a political subject in the modern world requires adjustment [1]. It is obviously related to the fact that the ratio of economic and political behavior of the subjects has a certain peculiarity, as it is strengthening or reducing due to other factors. Studies of socio-economic and socio-political activity of young people are based on the idea of young people's gradual inclusion into social participation and characterize their substantial aspects and determinants. Thus, I.V. Arendachuk states that senior students show orientation towards professional and other types of economic activity (including various forms of incomes through the Internet, MLM, etc.), while political activity becomes the major component of social activity [2]. Sociological studies show that the perspective of independent economic activity of the Russian student youth is not high [3], however, real, sporadic or constant economic behavior that is typical of the majority of young people [4].

Since social activity of young people is multidimensional, different forms of activity coexist. The study mentioned above shows that if junior students (first and second years) do not include economic and political activity into one factor, the situation is the opposite in senior students (third and fourth years) [2].

Socio-political activity of young people is a factor and consequence of personal and social development [5], [6], [7]. Recent studies prove the dependence of socio-political activity of the Russian youth from the growing trends related to cosmopolitan civil views [8]. Analysis of political socialization of the Russian youth brings us to the conclusion related to their inclusion into political culture of the modern culture aspects. On the one hand, there is fear of risk, on the other hand, there is a desire to risk, because risk is seen as a coping function when dealing with pressure on behalf 
of institutional social structures [1]. At the same time, study of the relationship between riskiness, envy, and nature of social activity has shown that envious young people use the activity strategy that is associated with risks, while young people that are not envious use the careful activity strategy [9]. In other words, risk related to social activity can be related to various motives and settings [10], [11]. This is also true about young people's political activity. In the study by I.V. Vasenina \& G.B. Pronchev [12] it has been pointed out that modern Russian youth perceives the political sector as a source of material income, i.e. political and economic activity are interconnected.

Thus, it is important which socio-psychological factors determine socio-economic and socio-political activity of young people to a greater extent and what their role in this determination is.

The purpose of this investigation is to study the directions of connections between the preference of socio-economic and socio-political activity by young people and satisfaction of basic needs, riskiness, preference for sources of information about the public life of the country, attitudes towards the possibility of participation in social life and social activity in the country of residence

\section{Methodology}

305 people took part in the investigation, mean age $\mathrm{M}=21.2 \mathrm{SD}=2.9$ (35\% male), $64 \%$ of the respondents that filled out the questionnaires and surveys were residents of a big city, $36 \%$ of the respondents were residents of a small town (up to 100000 residents) in the Russian provincial regions. The study defined socio-demographic indicators (gender, age, income, marital status, education, place of residence). The scales developed by the authors of the study were used with a dimension of 5 points in accordance with the Likert scale to study commitment to a particular type of activity (general social activity, political and economic activity), the source of information about public life in the country (television (TV), radio (RD), Internet (IN), friends (FR), parents (PR), social networks (NW), newspapers (PP), representatives of parties or organizations (OR)), convictions (regarding the fact that the country has all the possibilities for participation in public life (to be a member of a party, participate in elections, rallies, campaigns, etc.) and that the respondent personally has this opportunity; about the degree of parents' social activity).

In order to identify needs' satisfaction for autonomy, competence and connectedness, we used the Scale of Basic Needs Satisfaction (SBNS) developed by Mary M. Johnston, Sara J. Finney (the need for autonomy, competence, and relations with others) [13]; in order to identify extreme risk behavior we used the scale called "Self-assessment of propensity to extreme risk behavior" (search for strong sensations (R1); intolerance of monotony (R2); search for new impressions (R3); non-adaptive desire for difficulties (R4)) [14], Sensation Seeking Scale (Zukerman) [15].

\section{Results and Discussion}

Comparison of indicators of adherence to a certain type of activity allows us to conclude that economic activity is more expressed unlike political activity which is less expressed. It should be noted that variability of indicators is also stronger in terms of economic activity, which indicates heterogeneity of estimates of adherence to it (high evaluation alternates with low evaluation).

The study that has been conducted shows that commitment to diverse social activity (ActB) is associated with a large number of variables. This suggests that variables that are analysed determine young people's activity to various extents.

Correlation analysis helped to establish that commitments to diverse social activity, as well as socio-political and socio-economic activities are closely interrelated. However, there is no direct relationship between commitment to economic, political activity and socio-demographic characteristics, income of respondents.

On the other hand, there are links mediated with other indicators, particularly, through adherence to sources of information about public life in the country (radio, television, representatives of political and other organizations). It should be pointed out that we did not trace any interrelations between commitment to socio-political and socioeconomic activity and the use of television (TV) and social networks (NW) to obtain information about public life, which is somewhat inconsistent with previously obtained research results [16].

This data also shows a significant relationship between activity and parents' participation in the public life of the country (PA), as well as the conviction that there are all possible opportunities (SI) to do this (become a party member, participate in elections, rallies, attend training sessions / sections, attend religious services, etc.), there are personal opportunities (PI as well). Indicators of proneness to risk (R1-R4) (search for strong sensations and search for new impressions) are associated only with commitment to young people's socio-economic activity.

\begin{tabular}{|l|r|r|r|r|r|}
\hline Parameters & M & \multicolumn{1}{c|}{ SD } & \multicolumn{1}{c|}{ ActB } & \multicolumn{1}{c|}{ SE } & \multicolumn{1}{c|}{ PA } \\
\hline Sex & 1.35 & 0.48 & $-.12^{*}$ & -.04 & .01 \\
\hline Age & 21.22 & 2.96 & $-.19^{* *}$ & -.06 & -.07 \\
\hline Fam & 1.29 & 0.56 & -.06 & 0 & -.03 \\
\hline Ed & 3.75 & 0.95 & $-.12^{*}$ & 0 & -.05 \\
\hline En & 2.95 & 0.73 & -.01 & .06 & 0 \\
\hline PA & 2.07 & 1.05 & $.28^{* *}$ & $.15^{* *}$ & $.21^{* *}$ \\
\hline S1 & 3.09 & 1.19 & $.19^{* *}$ & $.28^{* *}$ & $.13^{*}$ \\
\hline P1 & 2.73 & 1.17 & $.28^{* *}$ & $.24^{* *}$ & $.24^{* *}$ \\
\hline TV & 2.57 & 1.23 & .07 & .04 & $.15^{* *}$ \\
\hline
\end{tabular}


Helix Vol. 9 (1): 4813- 4817

\begin{tabular}{|l|r|r|r|r|r|}
\hline RD & 1.54 & 0.83 & $.18^{* *}$ & $.16^{* *}$ & $.24^{* *}$ \\
\hline IN & 4.48 & 0.82 & $.22^{* *}$ & $.13^{*}$ & .01 \\
\hline FR & 3.40 & 1.06 & $.13^{*}$ & .05 & .09 \\
\hline PR & 3.02 & 1.20 & $.20^{* *}$ & .06 & $.18^{* *}$ \\
\hline NW & 3.99 & 1.16 & $.18^{* *}$ & .06 & .04 \\
\hline BK & 2.17 & 1.10 & $.27^{* *}$ & .09 & .09 \\
\hline OR & 1.96 & 1.00 & $.32^{* *}$ & $.17^{* *}$ & $.25^{* *}$ \\
\hline AUT & 4.91 & 0.88 & .05 & .04 & -.04 \\
\hline KOM & 4.43 & 0.83 & $.15^{*}$ & $.22^{* *}$ & .05 \\
\hline RED & 4.73 & 0.79 & $.11^{*}$ & .11 & -.05 \\
\hline R1 & 4.88 & 2.41 & $.23^{* *}$ & $.15^{*}$ & -.02 \\
\hline R2 & 4.08 & 2.68 & .03 & -.01 & -.07 \\
\hline R3 & 3.54 & 1.95 & $.17^{* *}$ & $.12^{*}$ & .04 \\
\hline R4 & 3.55 & 2.19 & $.12^{*}$ & .08 & -.01 \\
\hline ActB & 2.21 & 0.55 & 1 & $.58^{* *}$ & $.55^{* *}$ \\
\hline SE & 2.69 & 1.37 & $.58^{* *}$ & .1 & $.27^{* *}$ \\
\hline PA & 1.73 & 0.94 & $.55^{* *}$ & $.27^{* *}$ & 1 \\
\hline
\end{tabular}

Table 1: Mean, Standard Deviations and Pearson Correlations

As a result of structural modeling, it was established that the most appropriate model $(\chi 2=29.30 ; \mathrm{df}=28 ; \mathrm{p}=.398$; $\mathrm{CFI}=.997$; GFI $=.983$; RMSEA $=.012)$ includes the following influencing variables: convictions regarding possibilities of social activity in a country, parents' social activity experience, adherence to specific sources of information (radio and representatives of organizations), satisfaction of basic needs for autonomy and competence, as well as riskiness. The objective influencing variable is the exogenous variable "age". It allows to identify the link direction.

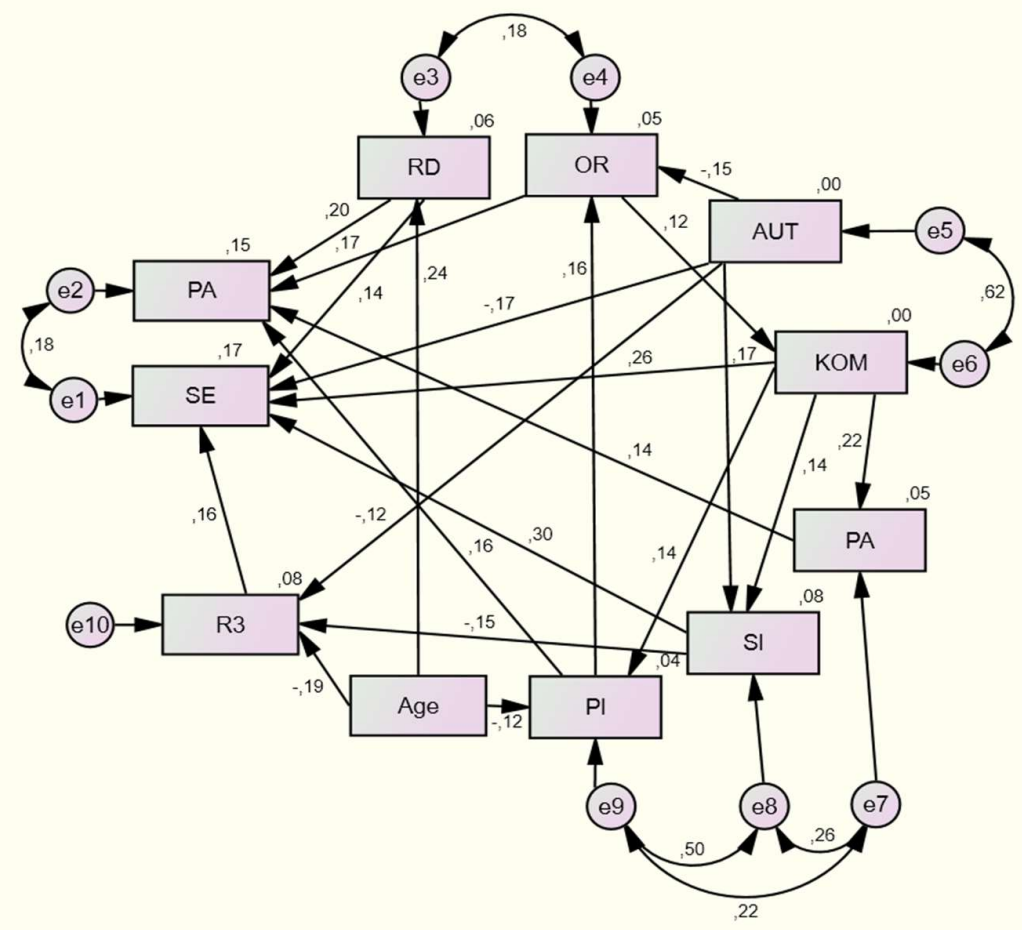

$\mathrm{CMIN}=29,298 ; \mathrm{df}=28 ; \mathrm{p}=, 398 ; \mathrm{CFI}=, 997 ; \mathrm{GFI}=, 983$;

RMSEA=,012; PCLOSE $=, 970$

Figure 1: The Best-Fit Structural Equation Model including Activity, Attitudes, Basic Needs Satisfaction, Using Information Instances 
It has been established that variables that influence variations in preferences of economic and political activity are both socio-psychological variables, that are associated with socialization of an individual (sources of information about social life, experience of parents' participation in social life, social attitudes regarding possibilities of participation in public life), and personal variables, which include satisfaction of basic needs, i.e. in autonomy (negatively) and competence (positively), riskiness (search for new impressions). It is clear from the model that the belief that a country has all the possibilities for social life participation and search for new impressions mediate the influence of satisfaction of the need for autonomy on young people's preference for socio-economic activity, which is weakening this influence.

This means that satisfaction of the need for autonomy reduces young people's preference for economic activity, and the conviction that there are many opportunities in the country and riskiness weaken this connection and determine socio-economic activity. The conviction that there are opportunities for social activity in the country mediates the influence of satisfaction of the need for competence on economic activity, while the conviction that the respondent personally has this opportunity and the assessment of parental participation in public life in the country act as the moderator of influence of the need for competence on socio-political activism. In other words, the need for competence directly influences only economic activity; its influence on political activity is mediated by two attitudes - the parents' activity attitude and personal possibility of social inclusion attitude.

It should be noted that the overall impact of these variables on commitment to economic and political activity is small ( $15 \%$ and $17 \%$ of the total dispersion, respectively). This means that there are other variables that determine these types of activity. Research has to be carried out to analyse the contribution of values to preferences for these types of activity.

\section{Conclusion}

Commitment to social and economic activity among young people is expressed and variable, which means that, along with economically active ones, there are economically passive young people. Commitment to political activity is much lower and more homogeneous.

Correlation analysis of variables allowed to establish the lack of connection between general social activity and family status and income, as well as adherence to television sources of information about social life in the country. Results show that young females that continue their education are characterized by higher level of activity. The presence of a large number of correlations indicates significant determination of the general social activity of young people through the indicators of basic needs, adherence to certain information sources (radio, Internet, social networks, friends, parents, newspapers, representatives of parties and organizations) regarding social life in the country, attitudes and riskiness.

Satisfaction of the need for autonomy and competence directly determines economic activity of young people and indirectly determines socio-political activity, i.e. through attitudes to possibilities of social activity in the country (personal and in general) and parents' participation in public life (the need for competence). Adherence to a certain source of information (radio and representatives of organizations) about life in the country determines young people's political activity directly and acts as a mediator of the impact of the basic need for autonomy on this activity. In general, the power of attitudes in the determination of activity is higher than the strength of basic needs.

\section{Acknowledgement}

This work was supported by the Russian Science Foundation, grant № 18-18-00298

\section{References}

[1] Kirdjashkin IV. A Prefigurative Aspect of Political Socialization of Modern Youth and its Features. The Bulletin of Irkutsk State University. Series Political Science and Religion Studies, 2018, 23, p.32-38. doi: https://doi.org/10.26516/2073-3380.2018.23.32

[2] Arendachuk IV. Dynamics of Value and Meaning Characteristics of Social Activity of Modern Youth. RUDN Journal of Psychology and Pedagogics, 2018, 15(3), p.287-307. doi: 10.22363/2313- 1683-2018-15-3-287307

[3] Savchenko IA., Ageeva NA., Rodzikovskaya TA. Economic knowledge and economic consciousness. Authority, 2018, 26(4), p. 84-89. doi: 10.31171/vlast.v26i4.5768

[4] Konstantinovskiy DL. Russian Youth in the Formation and Use of Intellectual Potential. Sociological Science and Social Practice, 2017, 5(4), p. 46-64. doi: 10.19181/snsp.2017.5.4.5519

[5] Kahne J \& Bowyer B. The Political Significance of Social Media Activity and Social Networks. Political Communication. 2018, 35(3), p. 470-493. doi: 10.1080/10584609.2018.1426662

[6] Shiratuddin N, Hassan S, Mohd Sani MA., Ahmad MK., Khalid KA., Abdull Rahman NL., Ahmad NSY. Media and youth participation in social and political activities: Development of a survey instrument and its critical findings. Pertanika. Journal of Social Sciences and Humanities, 2017. 25, p. 1-19. http://pertanika.upm.edu.my/cspecial_issues.php?jtype=3\&journal=JSSH-25-S-6

[7] McFarland DA, Thomas RJ. Bowling Young: How Youth Voluntary Associations Influence Adult Political Participation. American Sociological Review, 2006.71 (3), p. 401-425. 
[8] Detochenko L, Magranov A. Civil identity of modern students: features and factors of transformation. Sociological Studies, 2018, 8, p.108-116. doi: 10.31857/S013216250000766-5

[9] Shamionov RM. Envy and Monetary Attitudes of Personality. Advances in Public, Environmental and Occupational Health, 2014, 4, p. 43-48. doi.10.5729/apeoh.vol4.43

[10] Shamionov RM. Factors of Social Activity of the Student Youth in Modern Russia. ICERI2018 Proceedings, 11th International Conference of Education, Research and Innovation November 12th-14th. Seville, Spain; 2018, p. 9543-9548. doi: 10.21125/iceri.2018.0077

[11] Grigoryeva MV. Evaluation of young people's social activity by representatives of another generations. ICERI2018 Proceedings, 11th International Conference of Education, Research and Innovation November 12th-14th, 2018. Seville, Spain; p. 7491-7495. doi: 10.21125/iceri.2018.0338

[12] Vasenina IV, Pronchev GB. Virtual social environments as a tool for motivating young people to social and political activities. Sociodynamics, 2018, 4, p. 1-11. doi: 10.25136/2409-7144.2018.4.25972 https:// nbpublish.com/library_read_article.php?id=25972

[13] Johnston MM, Finney SJ. Measuring basic needs satisfaction: Evaluating previous research and conducting new psychometric evaluations of the Basic Needs Satisfaction in General Scale. Contemporary Educational Psychology, 2010, 35, p. 280-296.

[14] Raygorodsky DYa. Practical psychodiagnostics. Methods and tests. Samara: publishing House "BAHRAHM"; 2001. 672 p.

[15] Zuckerman M. Item revisions in the sensation seeking scale. Personality and Individual Differences, 1996, 20(4), p. 515-515. doi: 10.1016/0191-8869(95)00195-6.

[16] Ushkin SG. "People against": protests and protesters in virtual social networks. Moscow: INFRA-M; 2018. doi:10.12737/monography_5b5ffb29e84668.61830970 